\title{
Estrategia de Industrialización Orientada a las Exportaciones: una forma de competitividad México-Brasil 1980-2003
}

\author{
Export-Oriented Industrialization \\ Strategy: a form of Mexico-Brazil \\ competitiveness1980-2003
}

DOI: https://doi.org/10.17981/econcuc.42.1.2021.Org.2

Artículo de investigación.

Fecha de recepción: 11/06/2020

Fecha de devolución: 18/09/2020

Fecha de aceptación: 10/10/2020

Fecha de publicación: 19/10/2020

\section{Elías Gaona Rivera}

Universidad Autónoma del Estado de Hidalgo. Pachuca de Soto, Hidalgo (México) saile2519@yahoo.com.mx

\section{Danae Duana Ávila}

Universidad Autónoma del Estado de Hidalgo. Pachuca de Soto, Hidalgo (México) duana@uaeh.edu.mx

Para citar este artículo:

Ganoa, E. \& Duana, D. (2021). Estrategia de Industrialización Orientada a las Exportaciones: una forma de competitividad México-Brasil 1980-2003. Económicas CUC, 42(1), 153-167. DOI: https://doi. org/10.17981/econcuc.42.1.2021.Org.2

\begin{abstract}
Resumen
La crisis económica acaecida en México en 1982 constituyó un parteaguas para su economía. Al analizar las estrategias de industrialización implementadas en México y Brasil, a partir de una investigación de tipo descriptiva utilizando una metodología cuantitativa, donde se examinaron las estrategias de industrialización orientadas a las exportaciones entre las dos economías, era indiscutible la necesidad de reestructurar su aparato productivo, para reincentivar su ciclo de acumulación capitalista, por lo que el país se vio en la necesidad de emprender reformas macroeconómicas. Entre los grandes reajustes que experimentó, sobresale la apertura económica, la cual ha pretendido en términos globales, propiciar el cambio estructural, principalmente a través de la activación de las industrias fabriles más dinámicas, las cuales debían convertirse en el motor del crecimiento económico. Con este nuevo proyecto de desarrollo, el Estado tenía que ceder su papel intervencionista y debía dejar paso para que las fuerzas del mercado solucionaran los problemas estructurales* que la industrialización sustitutiva ocasionó. Por lo tanto se propuso una pregunta fundamental: ¿La estrategia de desarrollo de Industrialización Orientada a las Exportaciones (IOE), de orientación meramente neoclásica, verdaderamente posibilitará solventar las dificultades estructurales de México, de tal forma que se avance sobre una senda continua de crecimiento en el largo plazo?

Palabras clave: Industria; manufactura; importaciones; comercio
\end{abstract} internacional; efectos multiplicadores

\begin{abstract}
The economic crisis that occurred in Mexico in 1982 was a watershed for its economy. When Analyzing the industrialization strategies implemented in Mexico and Brazil, from a descriptive research using a quantitative methodology, where the export-oriented industrialization strategies between the two economies were examined, the need to restructure their productive apparatus was indisputable, to reincentivize its capitalist accumulation cycle, for which the country saw the need to undertake macroeconomic reforms. Among the great readjustments that it underwent, the economic opening stands out, which has sought in global terms, to promote structural change, mainly through the activation of the most dynamic manufacturing industries, which should become the engine of economic growth. With this new development project, the State had to give up its interventionist role and had to make way for market forces to solve the structural problems that substitute industrialization caused. Therefore, a fundamental question was posed: Will the purely neoclassical Export-Oriented Industrialization (IOE) development strategy truly make it possible to solve Mexico's structural difficulties, so that progress is made on a continuous path of growth in the long term? Keywords: Industry; manufacture; imports; international trade; multiplier effects
\end{abstract}

* Calificativo que se aplica en economía a los aspectos o fenómenos más permanentes y menos influidos por las circunstancias ambientales. 


\section{INTRODUCCIÓN}

El modelo económico actualmente vigente, impulsado por la mayor parte de los gobiernos nacionales, así como por los organismos e instituciones internacionales, puede denominarse Industrialización Orientada a las Exportaciones, aunque algunos autores prefieren denominarla modelo neoliberal. Esto se refiere a él empleando el primer concepto, abreviado como IOE.

En la IOE, los gobiernos procuran no involucrarse directamente en la producción, sino sólo facilitar las actividades de las empresas privadas, creando condiciones propicias para su desempeño. La IOE se impuso como alternativa ante el agotamiento del modelo anterior, que en los países subdesarrollados fue la Industrialización por Sustitución de Importaciones, apoyada, a su vez en tres ejes: Protección, Regulación y Fomento. Este modelo estuvo vigente durante algunas décadas en América Latina, sin embargo, se agotó y desembocó en la crisis de la deuda externa. La excesiva, permanente e indiscriminada sobreprotección operó en contra de las exportaciones. La sobrerregulación creó monopolios y oligopolios que hacían ineficiente la asignación de los recursos. El fomento, general, indiscriminado y permanente, propicio la formación de empresas de baja competitividad internacional.

La crisis estructural del modelo de industrialización de sustitución de importaciones reorientó, en 1982, el estilo de la economía en algunos países de América Latina ${ }^{1}$. A partir de entonces, en un entorno de globalización económica mundial, el papel asignado a la industrialización orientada a la exportación destacó como objetivo de la política económica interna, en virtud de representar las posibilidades tanto de la modernización como de la especialización productiva para la exportación, que permitiera mejores tasas de crecimiento económico.

Desde 1983, en México, los lineamientos neoliberales de la política económica incorporaron una estrategia orientada al sector manufacturero nacional, mediante las políticas de ajuste primero y de estabilización después. En este sentido, suponiendo la modernización industrial, el sector manufacturero exportador se ubicó como el pretendido eje dinámico y de empuje de la integración productiva del conjunto de la actividad económica de México.

En tal sentido, el presente analiza las estrategias de industrialización que han implementados México y Brasil las cuales se orientan para generar aumentos en sus exportaciones, obteniendo información acerca de sus exportaciones de sus sectores básicos y estratégicos. Se utilizó una metodología cuantitativa del tipo descriptivo y se aplicaron encadenamientos productivos utilizando los métodos de Chenery-Watanabe y Rasmusen, comparando la situación económica de los dos países.

\footnotetext{
${ }^{1}$ México reorientó su modelo de desarrollo a comienzos de los 80`s y Brasil a principios de los 90’s.
} 


\section{Desarrollo}

Dentro de los modelos de la IOE, el comercio internacional se convirtió en el motor de crecimiento económico ${ }^{2}$. La estrategia de industrialización orientada hacia la exportación surgió como teoría a partir de la experiencia de algunos países asiáticos cuyas tasas de crecimiento venían siendo espectaculares desde mediados de la década de los 60's del siglo XX. De acuerdo con Balassa (1978), Balassa y Williamson (1990), y Ramírez y Sarmiento (2020), la actuación favorable del crecimiento económico de esos países estaba asociada a una rápida expansión de sus exportaciones. Según estos autores la expansión de las exportaciones actúa como una máquina de crecimiento económico por varias razones que se relacionan entre sí. Las exportaciones mantienen una fuente de demanda de insumos domésticos. También suministran una partida de divisas, que aseguran el financiamiento de importaciones de bienes intermedios y de capital que son requeridas para incrementar el producto.

El argumento de los efectos multiplicadores de las exportaciones sobre el conjunto de la actividad ha sido uno de los razonamientos más notables de los teóricos de los modelos de la IOE cuando aluden al sector exportador como determinante elemental del crecimiento. La idea esencial se basa en la participación activa de las economías a nivel internacional, no sólo se benefician de los efectos estáticos, resultado de una especialización por ventajas comparativas en costos, sino que también se consigue una mayor incidencia sobre el crecimiento económico derivado de los efectos dinámicos que proceden, particularmente, del cambio tecnológico ${ }^{3}$.

El mismo Balassa (1989), a fines de los ochenta, se referiría a los efectos dinámicos de la expansión de las exportaciones sobre el crecimiento económico:

Las exportaciones generarán un crecimiento de la demanda de insumos domésticos, a la vez, que al incrementarse el ingreso nacional - a través de los ingresos provenientes de las exportaciones y aquéllos derivados del incremento de la demanda interna de insumos - aumentará la demanda y, por lo tanto, la producción de bienes de consumo doméstico. Al mismo tiempo, las exportaciones se convierten en una importante fuente de divisas para la adquisición de importaciones de bienes intermedios y de capital necesarios para enfrentar el incremento de la producción interna. El dinamismo que se imprime al sistema mediante los beneficios derivados del comercio, dará lugar a una mayor estabilidad, lo que alentará las inversiones, las que al combinarse con un crecimiento significativo de la producción permitirán el aprovechamiento de economías de escala y la posibilidad de propiciar cambio tecnológico (1989, p. 296).

Algunos teóricos de los modelos de la IOE, muestran que la industrialización por sustitución de importaciones, que fue ejecutada como una forma de aminorar la dependencia económica mundial, intensifica dicha dependencia, debido a que las

\footnotetext{
${ }^{2}$ Para Prado (1999), el comercio es motor del crecimiento económico, pero sólo para países pequeños — poco poblados y de territorio reducido-; para los países grandes el motor de su crecimiento económico es el mercado interno.

${ }^{3}$ Dussel (1997) indica que una de las diferencias fundamentales entre los modelos IOE y el modelo HOS, es que los primeros además de considerar los efectos estáticos del comercio, ponen especial énfasis en los efectos dinámicos, mientras el HOS se concentra únicamente en los efectos estáticos.
} 
actividades sustitutivas de importaciones son intensivas en importaciones, demandando compras al exterior de insumos intermedios y bienes de capital para mantener su propia producción y crecimiento. Esto incita una elevada vulnerabilidad de la economía a las variaciones en el intercambio internacional. En contraste, se insinúa que el fomento de las exportaciones parece aminorar la dependencia, en el sentido de que las ganancias del comercio internacional se incrementan vertiginosamente, los mercados llegan a ser crecientemente diversificados y la economía se vuelve más flexible (Krueger, 1990; Ramírez y Sarmiento, 2020).

En la política industrial, las metas macroeconómicas giran en torno al libre comercio, la apertura económica, la supresión de barreras arancelarias y no arancelarias, medidas anti inflacionistas y políticas fiscales como monetarias restrictivas. Metas que al combinarse con las condiciones microeconómicas - determinado por un sector privado concebido como motor del desarrollo- darán lugar al proceso de industrialización. Se puede establecer que el desarrollo industrial puede ser visto como una consecuencia de unas condiciones macroeconómicas óptimas, derivadas de la competencia perfecta y la actuación libre de las fuerzas de mercado (Dussel, 1997).

Para lograr el éxito económico, resulta fundamental una política comercial óptima aunada a la estabilización macroeconómica. La liberalización económica y el fomento a las exportaciones deben ser implementadas para alcanzar la meta del crecimiento económico sostenido. El buen funcionamiento macroeconómico propiciará cambios en las condiciones macroeconómicas. Se trata de que un buen desempeño de las empresas puede ser el resultado de políticas que provean incentivos a las exportaciones, y a las industrias dirigidas al mercado doméstico, lo que evita la discriminación. Dichas políticas pueden suministrar un estímulo al crecimiento económico continuo por medio del cambio tecnológico, el cual es asumido en respuesta a la competencia con el exterior; aumentando el ahorro y por el más eficiente uso de factores (Balassa, 1982).

De acuerdo con lo expuesto arriba sobre la existencia de ciertos elementos que permiten el crecimiento económico en el largo plazo. La economía mexicana, a casi 30 años de haber adoptado una estrategia de IOE, debería de haber alcanzado una senda de crecimiento estable. Sin embargo, no sólo se trata de lograr que el sector manufacturero exportador se convierta en la pieza clave del modelo ni, en consecuencia, que se logre la transformación del patrón de especialización comercial -de una economía caracterizada por especializarse en las exportaciones de bienes primarios, a una economía cuyos principales productos a exportar son bienes industriales de relativamente alta intensidad tecnológica- sino también de analizar si las recomendaciones y predicciones de los modelos de IOE de inspiración neoclásica se han cumplido y, de ser así, dichas recomendaciones posibilitan la consecución de una trayectoria de crecimiento estable a largo plazo. Es decir, se intenta determinar si el éxito exportador de algunas industrias se ha alcanzado, o se está transitando sobre una senda de crecimiento estable en el largo plazo. Por lo anterior, resulta pertinente contrastar, en la medida de lo posible, la evidencia empírica con la argumentación neoclásica. 
Efectos Multiplicadores de la Expansión de las Exportaciones a través de los Encadenamientos Productivos hacia atrás y hacia adelante

Según la teoría neoclásica, el crecimiento económico debe lograrse a partir de la congruencia de un círculo virtuoso determinado por la expansión de las exportaciones. Esto es, según este planteamiento neoclásico, una estrategia de IOE tiene impacto positivo sobre el conjunto de la actividad económica, lo que se explica por el efecto multiplicador que tiene el crecimiento exportador sobre el resto de los sectores productivos a través de cuatro canales: 1) las relaciones insumo-producto y los cambios en el ingreso; 2) el impacto positivo sobre el empleo de los factores de la producción ociosos; 3) la mayor capacidad de utilización y la explotación de economías de escala; y 4) la facilidad de obtener divisas mediante los ingresos sobre exportaciones para la adquisición de las importaciones, que supone el crecimiento económico (Balassa, 1982; Krueger, 1990).Con la idea de corroborar si el modelo de IOE ha permitido superar las ineficiencias estructurales (desarticulación productiva y alta dependencia externa), que de acuerdo con las críticas más agudas de los teóricos neoclásicos habían provocado cuarenta años de ISI, en la presente sección, únicamente se abordarán los dos canales que tienen mayor relación con tales ineficiencias: las relaciones insumo-producto y la facilidad de obtener divisa para la adquisición de importaciones.

Para determinar el efecto positivo de la expansión del sector exportador en las relaciones insumo-producto y el crecimiento del ingreso, es necesario introducir un indicador que permita medir el grado de articulación que presenta la economía mexicana. En el presente trabajo se considera que el mejor indicador para medir dicha articulación es el coeficiente de eslabonamientos, el cual mide las relaciones hacia adelante y hacia atrás de las diferentes ramas de actividad calculadas a partir de la matriz insumo producto.

Rasmussen (1956) y Chenery y Watanabe (1958) propusieron cuantificar el impacto directo de un sector sobre el resto de economía mediante el cálculo de los encadenamientos, para ello recogen las relaciones de producción y distribución entre las ramas utilizando la matriz de coeficientes técnicos. Estos autores consideran que los encadenamientos más significativos son aquellos cuyos efectos son superiores a la media, para esto combinan los siguientes criterios.

\section{Resultados y Discusión}

\section{Relaciones Intersectoriales en México y en Brasil}

A continuación se presentan los resultados del ejercicio de medición de los encadenamientos en la estructura productiva mexicana, mediante los métodos de Chenery-Watanabe y Rasmusen. Ambos métodos se desarrollaron basándose en la información de flujos intersectoriales contenida en la matriz insumo-producto. Se obtuvieron datos de tres años: 1970, 1980 y 2003. Las dos primeras, 1970 y 1980, presentan una desagregación de 53 ramas manufactureras, mientras que la última presenta menos, 34. Los primeros años guardan la misma estructura, no así el 
año del 2003. Sin embargo, se realizó un esfuerzo para poder realizar su comparación, manteniendo el número que le fue asignado a cada actividad económica por el Instituto Nacional de Estadística y Geografía (INEGI). Así por ejemplo, en 1980 la actividad económica de papel y carbón le correspondía el sector (31), y en el 2003 cambia al (21) por la actividad industria de papel (Tabla 1).

TABla 1.

Actividades fabriles clave de México, varios años.

\begin{tabular}{l} 
México, 1970, 1980 y 2003 \\
\hline (8) Minerales metálicos no ferrosos. \\
(24) Hilado y tejido de fibras blandas. \\
(31) Papel y cartón. \\
(33) Refinación de petróleo. \\
(34) Petroquímica básica. \\
(40) Otras industrias químicas. \\
(46) Industrias básicas del hierro y el acero. \\
(47) Industrias básicas de metales no ferrosos.
\end{tabular}

Fuente: Elaboración propia con dados datos de INEGI (1994).

\section{- Sectores clave de México}

En México, los sectores clave no han cambiado entre 1970 y el 2003 (Tabla 1), sin embargo, surgieron nuevos, tales como: (30) Fabricación de equipo de computación, comunicación, medición y de otros equipos, componentes y accesorios electrónicos, (31) Fabricación de equipo de generación eléctrica y aparatos y accesorios eléctricos y (32) Fabricación de equipo de transporte, y (61) la electricidad. Este último aparece como sector estratégico en los años de 1970 y 1980. Mientras que los sectores (30) y (31) y, en 1970 se encontraban ubicados como sectores independientes o islas; esta situación muestra el dinamismo que tienen los sectores económicos.

\section{- Sectores base o estratégicos de ambos países}

Dos sectores de ambos países coinciden como actividades estratégicas: agricultura y extracción de petróleo y gas (Tabla 2).

TABLA 2.

Actividades fabriles estratégicas de México y Brasil, varios años.

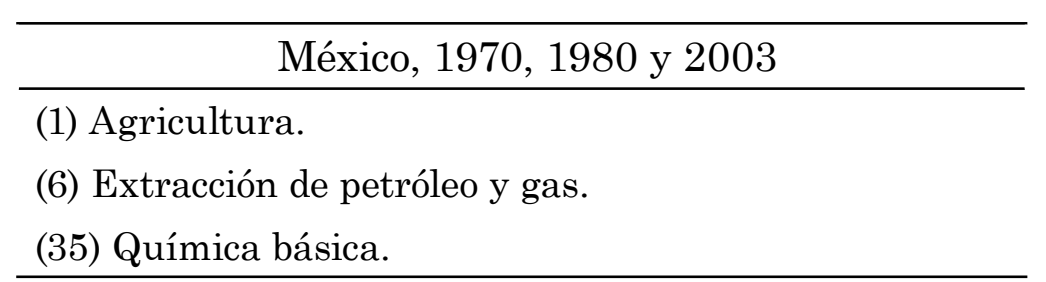

Fuente: Elaboración propia con dados datos de INEGI (1994). 


\section{- Sectores con fuerte arrastre o impulsores de la economía}

El sector (32) Fabricación de equipo de transporte, aparece como una actividad con un fuerte arrastre en 1970 y 1980, no así en el año 2003, que aparece como un sector clave. Por otro lado, parte del sector de alimentos y bebidas de México (11-15, 17, 19 y 21) de la Tabla 3, aparecen como actividades impulsoras de la economía. Las actividades febriles con un fuerte arrastre de la economía son: la textil (27) y (304), cueros y sus productos (28 y 305) y la industria del cemento (44 y 319). En México en 1970 y 1980 los sectores que tenían que ver con aparatos, equipos y accesorios electrónicos aparecían como sectores islas.

TABLA 3.

Actividades fabriles impulsoras de la economía de México, varios años.

México 1970, 1980 y 2003

(11) Productos cárnicos y lácteos.

(12) Envasado de frutas y legumbres.

(13) Molienda de trigo y sus productos.

(14) Molienda de nixtamal y productos de maíz.

(15) Procesamiento de café.

(17) Aceites y grasas vegetales comestibles.

(19) Otros productos alimenticios.

(21) Cerveza.

(25) Hilado y tejido de fibras duras.

(26) Otras industrias textiles.

(27) Prendas de vestir.

(28) Cuero y sus productos.

(29) Aserraderos incluso triplay.

(30) Otras industrias de la madera.

(36) Abonos y fertilizantes.

(39) Jabones, detergentes y cosméticos.

(44) Cemento.

(48) Muebles y accesorios metálicos.

(49) Productos metálicos estructurales.

Fuente: Elaboración propia con dados datos de INEGI (1994).

\section{- Sectores isla}

Como se puede observar la dinámica industrial ha cambiado a través del tiempo. Así por ejemplo, en México, en el año de 1970, la fabricación de equipo de cómputo, aparatos y accesorios electrónicos eran actividades islas, sin embargo, ahora son actividades clave. En otro sentido la producción de máquinas, aparatos, materiales eléctricos, automóviles, camionetas y camiones y otros equipos de transporte son sectores clave (Tabla 4). 
TABLA 4.

Actividades fabriles islas, México y Brasil, varios años.

México 1970, 1980 y 2003

(3) Silvicultura.

(4) Caza y pesca.

(7) Mineral de hierro.

(9) Canteras arena, grava y arcilla.

(10) Otros minerales no metálicos.

(16) Azúcar y subproductos.

(18) Alimentos para animales.

(22) Refrescos embotellados.

(23)Tabaco y sus productos.

Fuente: Elaboración propia con dados datos de INEGI (1994).

\section{Actividades clave y sectores exportadores}

Relacionando las actividades clave con las actividades altamente exportadoras, se observa que existe coincidencia entre ellas, sin embargo, los encadenamientos productivos, tanto hacia atrás como hacia adelante, del grupo II, han caído en la mayoría de sus sectores. Por su parte, en el grupo I no hubo predominio de caída o subida de los encadenamientos, porque en dos sectores - (15) industria de las bebidas y del tabaco y (23) fabricación de productos derivados del petróleo y del carbón- cayeron los encadenamientos tanto hacia atrás como hacia adelante, pero también en otros dos sectores - (28) fabricación de productos metálicos y (32) fabricación de equipo de transporte - hubo un crecimiento de los encadenamientos en ambos sentidos. Mientras que otro sector -(27) Industrias metálicas básicas— sufrió caída en su eslabonamiento hacia atrás, pero subió hacia adelante. Otro sector - (31) Fabricación de equipo de generación eléctrica y aparatos y accesorios eléctricos- lo hizo en sentido contrario, es decir, tuvo una subida hacia atrás y cayó hacia adelante (Tabla 5).

Los grupos III y IV de México ${ }^{4}$ han sufrido predominantemente caídas en sus eslabonamientos productivos. Por tanto, si se analizan todos los sectores económicos se encuentra que en casi la totalidad de las actividades económicas de los grupos I-IV han caído los encadenamientos productivos tanto hacia atrás como hacia adelante, sobresaliendo la caída del grupo II, considerado altamente exportador.

\footnotetext{
4 En los grupos exportadores menos dinámicos de México, III y IV también se está presentando una desarticulación productiva, en mayor medida que en Brasil, esta situación se podría deber a que este país adoptó una política de articulación productiva. Ferraro (2010) señala que este país ofrece el conjunto de experiencias más importante en América Latina en el marco de la implementación de la política de Aglomeraciones Productivas Locales (APL). La política de apoyo a APL en Brasil es el caso de mayor fortaleza en América Latina, en cuanto a niveles de cobertura geográfica y sectorial, así como en recursos, en materia de una política nacional concebida y estructurada para fomentar la articulación productiva como parte de la política industrial y de desarrollo productivo de un país. En otro documento Ferraro (s/f), manifiesta que Brasil cuenta con un fuerte desarrollo institucional al contar con El Servicio Brasileño de Apoyo a Micro y Pequeñas Empresas (SEBRAE), mientras que México es un país con una institucionalidad en proceso. El gasto destinado a Pymes, la fecha de creación de instituciones y el número de empleados fortalecen lo manifestado por Ferraro. El gasto en fomento a Pymes como porcentaje del PIB, en el 2005, fue de 0.085 y de 0.015, en Brasil y México, respectivamente. El SEBRAE se creó en el año de 1972 y en el 2005 contaba con 4500 empleados. Y hace apenas una década, en el 2001, se creó en México la Subsecretaría para la Pequeña y Mediana Empresa (SPYME), y contaba con tan sólo 283 empleados, a mitad de la década del 2000 (Ferraro, 2010).
} 
TABLA 5.

México. Coeficientes de encadenamiento hacia atrás y adelante 1980 y 2003.

\begin{tabular}{|c|c|c|c|c|}
\hline \multirow{2}{*}{ Grupo I } & \multicolumn{2}{|c|}{ Atrás } & \multicolumn{2}{|c|}{ Adelante } \\
\hline & 1980 & 2003 & 1980 & 2003 \\
\hline (15) Industria de las bebidas y del tabaco. & 0.99859 & 0.92533 & 0.66420 & 0.61047 \\
\hline $\begin{array}{l}\text { (23) Fabricación de productos derivados del petróleo y del } \\
\text { carbón. }\end{array}$ & 1.16046 & 1.08327 & 1.10612 & 1.08373 \\
\hline (27) Industrias metálicas básicas. & 1.17017 & 1.07010 & 1.24808 & 2.02927 \\
\hline (28) Fabricación de productos metálicos. & 1.01166 & 1.10183 & 0.96510 & 0.99951 \\
\hline $\begin{array}{l}\text { (31) Fabricación de equipo de generación eléctrica y } \\
\text { aparatos y accesorios eléctricos. }\end{array}$ & 0.95763 & 1.35095 & 1.77073 & 1.20806 \\
\hline (32) Fabricación de equipo de transporte. & 1.07547 & 1.19752 & 0.81139 & 1.06615 \\
\hline \multicolumn{5}{|l|}{ Grupo II } \\
\hline (18) Fabricación de prendas de vestir. & 1.17320 & 1.13833 & 0.70613 & 0.75835 \\
\hline $\begin{array}{l}\text { (19) Fabricación de productos de cuero, piel y materiales } \\
\text { sucedáneos, excepto prendas de vestir. }\end{array}$ & 1.14157 & 1.12362 & 0.79493 & 0.86052 \\
\hline (21) Industria del papel. & 1.08827 & 1.05843 & 1.41555 & 1.22226 \\
\hline (6) Extracción de petróleo y gas. & 0.71143 & 0.62310 & 2.09373 & 1.83502 \\
\hline $\begin{array}{l}\text { (23) Fabricación de productos derivados de petróleo y del } \\
\text { carbón. }\end{array}$ & 1.16046 & 1.08327 & 1.10612 & 1.08373 \\
\hline (25) Industria del plástico y del hule. & 1.12003 & 1.09172 & 1.24085 & 1.26613 \\
\hline \multicolumn{5}{|l|}{ Grupo III } \\
\hline (15) Industria de las bebidas y del tabaco. & 0.99859 & 0.92533 & 0.66420 & 0.61047 \\
\hline \multicolumn{5}{|l|}{ Grupo IV } \\
\hline (14) Industria alimentaria. & 1.13928 & 0.97176 & 0.79868 & 0.99850 \\
\hline (20) Industria de la madera. & 1.09459 & 0.90659 & 0.98480 & 0.81170 \\
\hline (22) Imprentas y editoriales. & 1.01747 & 0.98635 & 0.97640 & 0.64206 \\
\hline (24) Industria química. & 0.92544 & 0.99808 & 1.05330 & 2.47453 \\
\hline
\end{tabular}

Fuente: Elaboración propia con dados datos de INEGI (1994).

De acuerdo con la información mostrada hasta ahora, se deduce que a medida que se han ido consolidando los procesos de industrialización la economía mexicana ha presentado una menor integración. Es decir, que los coeficientes de los encadenamientos tenderían a crecer conforme las estrategias de desarrollo van afianzándose, pero todo indica que en México el concepto de integración va separado de los procesos de industrialización.

La falta de articulación productiva, precede a un problema mayor, el histórico déficit estructural en la balanza comercial característico de la economía mexicana. Si la política de desarrollo adoptada a partir de los años ochenta, pretendía impulsar a los sectores industriales más dinámicos- en términos de exportaciones- como motor del crecimiento económico, y estos sectores han logrado insertarse dentro de la dinámica mundial, basado en ventajas comparativas en costos, que tales industrias 
lograran "jalar" al resto de la actividad económica y constituirse como un grupo dinamizador, más que dinámico. En este sentido, donde queda el efecto positivo de la expansión de las exportaciones sobre el crecimiento del ingreso nacional y las relaciones insumo producto, si las ramas que comandan el crecimiento económico se alejan cada vez más de la dinámica interna.

El otro efecto multiplicador de la expansión de las exportaciones sobre el crecimiento económico es el que tiene que ver con la obtención de divisas, que permiten la adquisición de importaciones de maquinaria, equipo e insumos intermedios para la producción y que son necesarios para enfrentar el crecimiento de la producción interna (Balasa, 1989). Al respecto, se debe mencionar que, así como la apertura comercial permite la expansión de la actividad exportadora, también significa entrada de importaciones lo cual, por supuesto, podría tener implicaciones importantes en economías con estructuras productivas desarticuladas como la mexicana y brasileña.

En la medida en que la especialización comercial se fundamenta en el desenvolvimiento de actividades con una elevada propensión a importar, lo cual, junto con la existencia de sectores poco exportadores pero con una conducta fuertemente importadora, podría impedir que la obtención de ingresos sobre exportaciones cubra el monto de las importaciones necesarias para enfrentar la expansión de la producción y, con ello, imposibilitar la corrección del déficit comercial, acentuando el problema estructural del mismo.

El argumento anterior, se sostiene con la evidencia presentada hasta el momento, para medir el afecto que el aumento de las exportaciones tiene sobre la posibilidad de cubrir las importaciones en bienes intermedios y de capital sin generar profundos desequilibrios comerciales, se introducirán dos indicadores:

a. El ratio exportaciones/importaciones, el cual pretende determinar si efectivamente la apertura comercial, lejos de constituir un medio para el crecimiento desproporcionado de las importaciones, es capaz de generar el suficiente dinamismo económico que permita crecer sin generar estrangulamiento comercial.

b. La distribución de importaciones según tipo de bien, la que permitirá establecer si los recursos provenientes de las exportaciones se destinan a la compra de bienes de equipo que son tan necesarios para suplir la carencia de innovación tecnológica, tal como lo plantea la teoría ortodoxa.

En lo que se refiere al ratio exportaciones/importaciones, hay tres consideraciones que surgen de los datos de la Tabla 6, ratio exportaciones-importaciones. Primero, cuando se incluye a la industria a la industria maquiladora, como es lógico, la proporción por la cual los ingresos derivados de las exportaciones cubren las importaciones resulta mayor que cuando se excluye a este tipo de actividades, en casi 20 puntos porcentuales. Esto es, al incluir en la maquila, los ingresos provenientes de las exportaciones logran cubrir alrededor de $90 \%$ del monto de las importaciones, pero cuando se excluye a la industria maquiladora, los recursos generados por las exportaciones sólo alcanzan apagar a aproximadamente $70 \%$. 
TABLA 6.

México. Ratio exportaciones-Importaciones, 1993-2004.

\begin{tabular}{|c|c|c|c|c|}
\hline Gran División 3: Industria manufacturera & 1993 & 1995 & 2000 & 2004 \\
\hline \multicolumn{5}{|l|}{ Incluye industria maquiladora } \\
\hline Total de bienes & 0.76 & 1.13 & 0.90 & 0.92 \\
\hline División I: Productos alimenticios, bebidas y tabaco. & 0.52 & 1.13 & 0.72 & 0.58 \\
\hline División II: Textiles, prendas de vestir e industria del cuero. & 0.78 & 1.51 & 1.26 & 1.14 \\
\hline División III: Industria de la madera y productos de madera. & 0.82 & 1.18 & 0.93 & 0.63 \\
\hline División IV: Papel, productos de papel, imprentas y editoriales. & 0.15 & 0.34 & 0.4 & 0.39 \\
\hline $\begin{array}{l}\text { División V: sustancias químicas, derivados del petróleo, productos de } \\
\text { caucho y plásticos. }\end{array}$ & 0.46 & 0.75 & 0.45 & 0.51 \\
\hline $\begin{array}{l}\text { División VI: productos de minerales no metálicos, exceptuando } \\
\text { derivados del petróleo y carbón. }\end{array}$ & 1.18 & 2.04 & 1.48 & 1.24 \\
\hline División VII: industrias metálicas básicas. & 0.71 & 1.56 & 0.51 & 0.5 \\
\hline División VIII: productos metálicos, maquinaria y equipo. & 0.71 & 1.05 & 0.94 & 0.99 \\
\hline División IX: otras industrias manufactureras. & 0.55 & 0.72 & 0.61 & 0.69 \\
\hline \multicolumn{5}{|l|}{ Excluye industria maquiladora } \\
\hline Total de bienes & 0.58 & 1.05 & 0.70 & 0.74 \\
\hline División I: Productos alimenticios, bebidas y tabaco. & 0.46 & 1.08 & 0.68 & 0.54 \\
\hline División II: Textiles, prendas de vestir e industria del cuero. & 0.37 & 1.66 & 1.02 & 0.83 \\
\hline División III: Industria de la madera y productos de madera. & 0.41 & 1.00 & 0.5 & 0.25 \\
\hline División IV: Papel, productos de papel, imprentas y editoriales. & 0.1 & 0.29 & 0.3 & 0.32 \\
\hline $\begin{array}{l}\text { División V: sustancias químicas, derivados del petróleo, productos de } \\
\text { caucho y plásticos. }\end{array}$ & 0.41 & 0.7 & 0.38 & 0.46 \\
\hline $\begin{array}{l}\text { División VI: productos de minerales no metálicos, exceptuando } \\
\text { derivados del petróleo y carbón. }\end{array}$ & 1.08 & 2.12 & 1.51 & 1.21 \\
\hline División VII: industrias metálicas básicas. & 0.69 & 1.54 & 0.49 & 0.47 \\
\hline División VIII: productos metálicos, maquinaria y equipo. & 0.44 & 0.9 & 0.71 & 0.81 \\
\hline División IX: otras industrias manufactureras. & 0.24 & 0.37 & 0.3 & 0.4 \\
\hline
\end{tabular}

Fuente: Elaboración propia con datos de INEGI (1994).

Segundo, ni incluyendo a la maquila, la economía mexicana es capaz de obtener un monto suficiente de divisas a través de sus exportaciones para adquirir las importaciones que necesita y enfrentar el crecimiento económico del país. Solo en años de crisis está situación se revirtió, lo que se explica por la propia contracción económica que supone. Es decir, las dificultades en la cuenta corriente, derivadas de una alta propensión a importar de las actividades más exportadoras y de sus implicaciones sobre el estrangulamiento que provoca el aumento de las importaciones en el crecimiento económico.

Tercero, sólo una actividad manufacturera — productos minerales no metálicosfue capaz de cubrir sus importaciones a partir de los ingresos por exportaciones. La división de Productos minerales no metálicos pertenece al grupo III, el cual se caracteriza por un alto desempeño productivo pero un bajo dinamismo exportador. 


\section{Tipos de importaciones}

A la falta de capacidad de México de cubrir el monto de las importaciones con las divisas obtenidas por las exportaciones, se pregunta iel tipo de bienes importados son intensivos en el factor escaso-capital o tecnología- tal como supondría el modelo HOS? O lo que es lo mismo, si los recursos obtenidos por concepto de exportaciones mexicanas resultan insuficientes para las importaciones que requiere el crecimiento, se tendría que considerar si dichas importaciones, por lo menos se concentran en la adquisición de maquinaria y equipo, intensivos en el factor escaso en México, cuyos costos de producción internamente resultan superiores a los del mercado internacional, alcanzándose de esta manera una de las ganancias estáticas del intercambio.

En México, durante 24 años, 1950-1973, durante el proceso de sustitución de importaciones predominaron las importaciones de Bienes de Capital (BK), estas tuvieron una participación de $44.6 \%$ en las importaciones totales, le siguieron en importancia las importaciones de Bienes Intermedios (BI) con 35\% y los Bienes de Consumo (BC) con $21 \%$.

Sin embargo, a partir de 1974 su estructura cambió, al ser desplazados los bienes de capital por los bienes intermedios, éstos últimos representaron el 70.1\% de las importaciones totales entre el año de 1974 y el año 2010, por su parte los bienes de capital vieron mermada su participación al pasar de $46 \%$ a 19.1\%; de igual forma los bienes de consumo redujeron su representación a $10.8 \%{ }^{5}$. Las importaciones se concentran principalmente en los bienes de consumo intermedio, seguido por la de bienes de capital, con una diferencia de más de 50 puntos porcentuales. Ello conduce a cuestionar el modelo tradicional HOS, es decir dadas las características de la economía mexicana, los bienes que importaría el país serían en mayor medida bienes de equipo y capital, pero la evidencia muestra que la mayor proporción de importaciones se concentran en los insumos intermedios, los cuales no son más intensivos en capital que los primeros (Tabla 7).

TABLA 7.

Importaciones por tipo de bien, 1974-2010.

\begin{tabular}{lccccccccc}
\hline & \multicolumn{3}{c}{$1974-2010$} & \multicolumn{3}{c}{$1990-2000$} & \multicolumn{3}{c}{$2001-2010$} \\
\hline & BI & BK & BC & BI & BK & BC & BI & BK & BC \\
\hline México & 70.1 & 19.1 & 10.8 & 73.4 & 15.9 & 10.7 & 74.2 & 11.9 & 13.9 \\
\hline
\end{tabular}

Fuente: Elaboración propia con datos de INEGI varios años.

El alto porcentaje de importaciones de bienes intermedios se podría deber a que las actividades en las que se está especializando la economía mexicana son preferentemente de ensamble o de carácter maquilador, por lo que importa una alta proporción de estos bienes, lo que supone una baja integración y, por consiguiente, procesos de involución o retroceso en las actividades que generan más empleo o están ligadas en mayor medida al mercado doméstico y que podrían cumplir la función de abastecedo-

\footnotetext{
${ }^{5}$ Las cifras se calcularon con datos de INEGI, estadísticas históricas de México.
} 
ras de las industrias más exportadoras. O en el mejor de los casos, la economía mexicana se podría estar especializando en la producción de bienes que requieren para su elaboración insumos intermedios, con cierto grado de sofisticación o requerimientos técnicos más complejos, que los productores nacionales no son capaces de ofrecer, por lo que las importaciones en este tipo de insumos es alta; sin embargo, cuál sería la razón por la que las compras al exterior de bienes de capital hayan disminuido en 10 puntos porcentuales desde que comenzó el proceso de liberalización acelerada; mientras, en contraparte, las importaciones de bienes de consumo final han estado creciendo significativamente en términos de participación.

Por lo anterior, la estrategia de IOE demuestra carecer de los efectos multiplicadores sobre el crecimiento económico de México, incrementando los problemas estructurales asociados con la falta de articulación productiva y el aumento excesivo de las importaciones, muchas de las cuales comienzan a destinarse a la compra de bienes que la economía doméstica podría satisfacer plenamente.

La política de Brasil la podemos dividir en un periodo, la década de los 90’s. La cual se caracterizó por las reformas las cuales se orientaron al mercado: liberalización comercial, privatización y desregulación, al mismo tiempo se ponían en práctica antiinflacionarios: el "Plan Collor" de marzo de 1990; luego el Plan Real, progresivamente puesto en marcha entre junio de 1993 y julio de 1994. El Plan Real, es identificado en ocasiones sólo como un plan de estabilización, diseñado como un programa de profundos cambios de la economía y la sociedad brasileñas. Por otro lado, se impusieron las siguientes medidas: implementación de una nueva moneda (el real), tasa de cambio con paridad 1 real = 1 dólar, facilidades para las importaciones, control del gasto público, mantener el proceso de apertura económica y buscar medidas de apoyo para la modernización de las empresas.

A mediados de los ochentas, Brasil se había convertido en una de las economías cerradas del mundo, entre 1988 y 1993 la protección de los productos nacionales fue gradualmente reducida. Las dos reformas, que se dieron entre 1988 y 1989, disminuyeron los aranceles de 51 a 35 por ciento. La mayoría de las barreras no arancelarias fueron eliminadas en 1990, con la prohibición de importar productos informáticos hasta finales de octubre de 1992. En 1990 se anunció la reducción gradual de los aranceles de 32.25 a 14.9 en promedio aranceles nominales promedio de $32.2 \%$ en 1990 a 14.9\% en el segundo semestre de 1993 (Pinheiro, Giambiagi \& Moreira, 2001). La liberalización del comercio fue importante para los bienes de consumo: los aranceles para bienes de consumo durables descendieron 66 puntos porcentuales. Mientras que la eliminación de la lista negra 37, les dio a los consumidores nacionales acceso legal a bienes extranjeros que habían sido prohibidos por décadas.

Otro acontecimiento notable en la política comercial de Brasil fue la creación de Mercosur en 1991, un acuerdo comercial regional que comprende a: Argentina, Brasil, Paraguay y Uruguay. Mercosur ha sido clave en atraer Inversión Extranjera Directa a Brasil, lo que ayudó a convertir al país en una base regional de exportación para muchas empresas multinacionales. En general las exportaciones brasileñas a los miembros del Mercosur se incrementaron 235\% de 1991 al 2000, mientras las importaciones crecieron $244 \%$. 


\section{CONCLUSiOnes}

La estrategia de desarrollo fundamentada en el fomento al sector exportador no se ha traducido en crecimiento económico sostenido, al contrario, la expansión de las exportaciones no parece tener relación directa con el crecimiento del producto.

Por otro lado, pese a lo innegable que resulta la reconfiguración de la estructura productiva, el sector fabril exportador adquiere un papel protagónico, los problemas estructurales de la economía mexicana, lejos de superarse, se han profundizado con la aplicación del modelo de IOE de inspiración neoclásica.

Es decir, bajo este esquema de desarrollo, las características estructurales de la economía mexicana parecen conservarse. Del modelo sustitutivo de importaciones a la estrategia de apertura comercial y liberación económica, ha cambiado la orientación del modelo, pero no la mayoría de los problemas que condujeron a la crisis del decenio de los ochenta, como la desarticulación productiva, los grandes y persistentes desequilibrios comerciales y la excesiva dependencia de financiamiento externo.

A principio de los años ochenta, México y Brasil enfrentaron una crisis, la cual mostraba el agotamiento en el modelo de acumulación mostrando la necesidad de reestructurar el aparato productivo, dando lugar a una serie de ajustes macroeconómicos que se tradujeron en estrategias orientadas a la exportación generando una transformación en la estructura productiva, siendo el sector manufacturero el motor de desarrollo económico que intentaba promover las actividades como núcleo dinámico.

El desempeño del sector manufacturero, genero un crecimiento de las exportaciones y de la productividad laboral, además se generaron crecientes déficits comerciales asociados, en gran medida, a la falta de capacidad de la estructura económica para incorporarse en el nuevo modelo de acumulación.

La existencia de una industrialización selectiva, en la que la promoción de los sectores vinculados a la dinámica internacional y con un mayor desempeño productivo mantiene un círculo virtuoso de crecimiento, mientras otras actividades vinculadas a la lógica de la demanda interna. Sin embargo, el modelo de IOE adoptado no ha sido capaz de reducir la dependencia externa, como lo plantea la teoría tradicional, por el contrario, las actividades más dinámicas, son participes principales del crecimiento de las importaciones, sin que esto signifique que las actividades menos exportadoras no sean también importadoras.

\section{REFERENCIAS}

Balassa, B. (1989). Comparative Advantage Trade Policy and Economic Development. Harvester Wheatsheaf: New York University.

Balassa, B. (1982). Developmet Strategies and Economic Performance: A Comparative Analysis of Eleven Semi-industrial Economies. Washington: Work Bank.

Balassa, B. (1978). Exports and economic growth: Further evidence. Journal of Development Economics, 5(2), 181-189. https://doi.org/10.1016/0304-3878(78)90006-8

Balassa, B. \& Willianson, J. (1990). Adjusting to Success: Balance of Payments Policy in the East Asian Nic's (Policy Analyses in International Economics). Washington: Peterson Inst for Intl Economics. 
Chenery, H. \& Watanabe, T. (1958). An International Comparison of the Structure of Production. Econometrica, 26, 487-521. https://doi.org/10.2307/1907514

Dussel, E. (1997). La Economía de la Polarización. Teorìa y evoluciòn del cambio estructural de las manufacturas mexicanas 81988-1996. México, D.F.: UNAM.

Ferraro, C. (2010). Clústeres y politicas de articulación productiva en América Latina. Santiago de Chile: CEPAL-FUNDES.

Krueger, A. (1990). Comparative advantage and development policy twenty years later. [IUI Working Paper, No. 65]. Stockholm: IUI. Recuperado de https://www. econstor.eu/bitstream/10419/95077/1/wp065.pdf

INEGI. (1994). El ABC de las cuentas Nacionales. [Online]. Recuperado de http:// internet.contenidos.inegi.org.mx/contenidos/productos/prod_serv/contenidos/espanol/bvinegi/productos/historicos/1329/702825143848/702825143848.pdf

Phineiro, A. Giambiagi, F. \& Moreira, M. (2001). Brazil in the 1990: A successful transition? Río de Janeiro, Brasil. Available: https://web.bndes.gov.br/bib/jspui/ handle/1408/15704

Prado, L. (1999). Brasil: Políticas comerciales e industriales: evolución y perspectivas. En, CEPAL, Nuevas políticas comerciales en América Latina y Asia (pp. 147-193). Santiago de Chile: CEPAL. Disponible en https://repositorio.cepal.org/ handle/11362/2206?locale-attribute=en

Ramírez, J. \& Sarmiento, J. (2020). Nuevas tendencias geopolíticas globales. Económicas CUC, 41(2), 102-114. https://doi.org/10.17981/econcuc.41.2.2020.Org.6

Rasmussen, P. (1956). Studies in Inter-Sectorial Relations. [Thesis/dissertation]. North-Holland, Amsterdam.

\section{BIODATA}

Elías Gaona Rivera es Doctor en Historia por la Universidad de Barcelona (España). Maestro en economía por parte de la UAM-Azcapotzalco (México). Tiene el reconocimiento de perfil PROMEP, y las materias que actualmente imparte son: Historia Económica Latinoamericana e Historia del pensamiento Económico. Pertenece al grupo de investigación denominado Estudios Económicos. Sus publicaciones más recientes son: Neoliberalismo y sus Consecuencias en México e Industrialización dirigida a la exportación. Una estrategia de crecimiento duradera: México y Brasil. https://orcid.org/0000-0003-2630-219X

Danae Duana Ávila es Doctor en Economía por la Sección de Estudiantes de Posgrado de la Escuela Superior de Economía por el Instituto Politécnico Nacional (México); con Maestría en Economía Regional por el Centro de Investigaciones Socioeconómicas de la Universidad Autónoma de Coahuila (México). Licenciado en Economía por el Instituto Politécnico Nacional. Profesor-Investigador de la Universidad Autónoma del Estado de Hidalgo (México), y el Instituto de Ciencias Económico Administrativas-Administración. Líneas de Investigación: Modelos econométricos y desarrollo regional, reconocimiento a profesor de tiempo completo con perfil deseable por parte de la Subsecretaría de Educación Superior, Miembro del SNI C. https:// orcid.org/0000-0003-2286-2843 